\title{
Low 5-hydroxymethylcytosine level is an independent predictor of high histological grade in locally advanced breast cancer
}

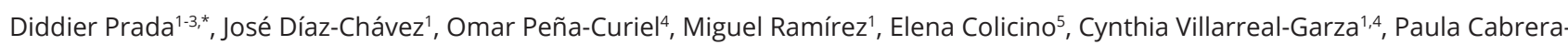
Galeana ${ }^{6}$, Thania Castro-Belio ${ }^{1}$, Nancy Reynoso ${ }^{1}$, Marco Andonegui ${ }^{1}$, Guiselle Navarro ${ }^{1}$, David Cantú de León ${ }^{1}$, Yolanda Villaseñor ${ }^{1}$, Alejandro López-Saavedra' ${ }^{1}$, Cristian Arriaga-Canon'1, Carlo C. Cortés ${ }^{1}$, Claudia Caro ${ }^{1}$, Abelardo Meneses Garcia ${ }^{1}$, Enrique Bargalló6,* and Luis A. Herrera ${ }^{1, *}$

'Unit for Biomedical Research in Cancer, Instituto Nacional de Cancerología $\square$ Instituto de Investigaciones Biomédicas, Universidad Nacional Autónoma de México, Mexico City, 14080, Mexico

${ }^{2}$ Department of Environmental Health Sciences, Columbia University Mailman School of Public Health, New York, 10032, USA

${ }^{3}$ Deparment of Biomedical Informatics, School of Medicine, Universidad Nacional Autónoma de México, Mexico City, 04510, Mexico

${ }^{4}$ Breast Cancer Center, Hospital Zambrano Hellion, Tecnológico de Monterrey, San Pedro de la Garza, N.L., 66278, Mexico

IIcahn School of Medicine, Mont Sinai, New York City, 10029, USA

${ }^{6}$ Unit of Breast Oncology, Instituto Nacional de Cancerología, Mexico City, 14080, Mexico

\begin{abstract}
Background: Breast cancer is a major cause of cancer mortality worldwide. In Mexico, most cases are diagnosed in locally advanced stages, which is associated with a poor prognosis. Recent studies have suggested that 5-hydroxymethylcytosine (5hmC) levels could be a prognostic marker in cancer. However, the role of $5 \mathrm{hmC}$ as a predictor of histopathological alterations in breast cancer have not been fully studied. Results: We evaluated samples from patients with breast cancer ( $N=141$ ), with a mean age of 50.12 yrs. (standard deviation [SD]: 9,54 yrs.), tumors showed a mean diameter of $6.53 \mathrm{~cm}(\mathrm{SD}: 3.06 \mathrm{~cm})$ at diagnosis, most of the patients showed overweight or obesity (77.3\%) and most of them were locally advanced stage $(n=111)$. A statistically significant and negative correlation between $5 \mathrm{hmC}$ levels and age in ER/PR-negative tumors ( $\beta=-0.028,95 \%$ confidence interval $[95 \% \mathrm{Cl}]$ : $-0.045,-0.010, p$-value $=0.005)$ and in triple negative tumors $(\beta$ $=-0.023,95 \% \mathrm{Cl}:-0.044,-0.001, p$-value $=0.046)$ was observed using mixed effects linear models. We also observed a negative correlation between $5 \mathrm{hmC}$ levels and an increased levels of cell proliferation markers, including Ki67 $(r=-0.16, p$-value $<0.01)$ and minichromosome maintenance complex component 2 [MCM2] $(r=-0.21, p$-value $=0.03)$. Finally, and using mixed effects models, we determined that the $5 \mathrm{hmC}$ level was an independent predictor of advanced histological grade in locally advanced breast cancer patients $(\beta=-0.077,95 \% \mathrm{Cl}$ $-0.142,-0.011, p=0.022$ ). We did not observe differences associated with complete pathological response or free-relapse survival according to $5 \mathrm{hmC}$ level. Conclusions: This study suggests that low $5 \mathrm{hmC}$ may serve as potential marker of adverse histopathological characteristics in locally advanced breast cancer patients, highlighting its potential as a useful clinical biomarker.
\end{abstract}

Keywords: 5-hydroxymethylcytosine; histological grade; biomarkers; cancer epigenetics

\section{Background}

Worldwide, breast cancer is the leading cause of cancer among women and is one of the most common causes of cancer-related death [1]. In developed countries, breast cancer is most frequently diagnosed at an early stage $[2,3]$ but in less developing countries, more than half of breast cancer cases are diagnosed as either locally advanced breast cancer (LABC) or as advanced breast cancer with distant metastases, which often involve the bones, liver, lungs or central nervous system [4-7]. LABC comprises clinical stages IIB to IIIC and is characterized by bulky tumors accompanied by regional lymph node metastases [8]. Compared with patients in early stages, patients with LABC have a higher recurrence risk and lower overall survivorship. According to the data from the Surveillance, Epidemiology and End Results (SEER) Program of the National Institutes of Health $(\mathrm{NIH})$, the 5-yr. overall survival rate for $\mathrm{LABC}$ patients is $85.3 \%$ but is $98.7 \%$ for patients with early stage disease. Moreover, 5-yr. survivorship

*Corresponding authors: Luis A. Herrera, Email: herreram@biomedicas. unam.mx; Enrique Bargalló-Rocha, Email: ebargallo@incan.edu.mx; Diddier Prada, Instituto Nacional de Cancerología - Mexico, San Fernando 22, Mexico City, Mexico, 14080, Tel.: +52-55- 56280400; Email: dpradao@incan.edu.mx

Received 8 January 2020 Revised 17 February 2020 Accepted 25 February 2020 Published 3 March 2020

Citation: Prada D, Díaz-Chávez J, Peña-Curiel O, Ramírez M, Colicino E, Villarreal-Garza C, Cabrera-Galeana $P$, Castro-Belio T, Reynoso N, Andonegui $M$, Navarro G, León DCD, Villaseñor Y, López-Saavedra A, Arriaga-Canon C, Cortés CC, Caro C, Garcia AM, Bargalló E, Herrera LA. Low 5-hydroxymethylcytosine level is an independent predictor of high histological grade in locally advanced breast cancer. J Cancer Res Ther 2020; 8(1):1-8. DOI: 10.14312/2052-4994.2020-1

Copyright: (c) 2020 Prada D, et al. Published by NobleResearch Publishers. This is an open-access article distributed under the terms of the Creative Commons Attribution License, which permits unrestricted use, distribution and reproduction in any medium, provided the original author and source are credited. 
in advanced breast cancer reaches only $27.0 \%$ [9], the diagnosis of breast cancer cases sometimes is challenging, because it is difficult to differentiate benign lesion only for clinical and some breast tumors have a high potential for metastatic spread in a short time following diagnosis. The effect of the histologic subtype on prognosis has been studied, but the results have been contradictory. Evidence has also been reported implying that the histologic subtype does not have a statistically significant role as a prognostic factor (5-yr. Disease Free Survival [DFS] rate), 71.8\% for spindle cell, $63.4 \%$ for squamous cell carcinoma, $69.2 \%$ for mesenchymal, $66.7 \%$ for fibromatosis-like, and $66.7 \%$ for mixed; 5 -year over-all (OS) rate, $76.2 \%$ for spindle cell, $75.5 \%$ for squamous cell, $80.8 \%$ for mesenchymal, $100 \%$ for fibromatosis-like, and $100 \%$ for mixed) [10]. Therefore, the discovery of new potential biomarkers that can be used for the early diagnosis and prediction of poor prognosis in LABC patients will improve the survival rates for these patients.

In general, there are three well-studied epigenetic markers, including histone modification, DNA methylation, and noncoding RNA-mediated silencing [11]. In cancer, the methylation of cytosine residues $(5 \mathrm{mC})$ in DNA is a wellstudied epigenetic process [12]. Global hypomethylation in malignant tumors and hypermethylation in regions densely populated with CpG dinucleotides (CpG islands), especially in the promoter regions of tumor suppressor genes, are now considered hallmarks of cancer [13-15]. Furthermore, a recently described epigenetic marker derived from the oxidation of $5 \mathrm{mC}$ to 5-hydroxymethylcytosine (5hmC), has been associated with malignancy, as well as with other physiological and pathological processes in humans [16]. $5 \mathrm{hmC}$ is produced from the enzymatic activity of the ten-eleven translocation family of enzymes (TET1, TET2, and TET3), which catalyze the oxidation of $5 \mathrm{mC}$ to 5-hydroxymethylcytosine, 5-formylcytosine, and 5 -carboxylcytosine $[17,18]$. Although the exact role of $5 \mathrm{hmC}$ has yet to be determined, $5 \mathrm{hmC}$ has been reported to play a critical role in the differentiation of pluripotent stem cells and progenitor cells, as well as in active demethylation of DNA [19-27].

An association between low 5hmC levels and cancer progression has been reported in hematologic malignancies $[28,29]$ and in solid tumors in organs such as the brain, lung, kidney, and liver [30-33]. Furthermore, 5hmC levels have also been reported to be lower in prostate, breast, and colon cancer tissues than in their normal tissue counterparts [30]. These data together suggest that the alteration of $5 \mathrm{hmC}$ could potentially contribute to tumorigenesis and progression of tumors [32]. In the clinical setting, low levels of $5 \mathrm{hmC}$ have been associated with poor outcomes, such as long-term prognosis and early recurrence, in different solid tumor cancers, including kidney cancer, esophageal cancer, and breast cancer [34-37].

A recent retrospective study published by Tsai et al., in which a semiquantitative technique (immunostaining) was used to measure $5 \mathrm{hmC}$ levels, reported an association between decreased $5 \mathrm{hmC}$ levels and poorer rates of disease-free survival and disease-specific survival in breast cancer patients, particularly patients with the triple negative subtype [35]. In this study, we used a quantitative technique (enzyme-linked immunosorbent assay, ELISA) to determine the association between relevant clinical and histopathological characteristics and $5 \mathrm{hmC}$ levels in fresh frozen tissue samples from a cohort of locally advanced and advanced breast cancer patients treated at the National Cancer Institute ( $\mathrm{NCl})$ in Mexico City.

\section{Methods}

\section{Experimental subjects}

The cohort included patients with $L A B C$ and advanced breast cancer treated at the $\mathrm{NCl}$ in Mexico City. The patients were recruited from 2013-2015 ( $N=141)$. The inclusion criteria included histopathological confirmation of breast adenocarcinoma, disease at a clinical stage of IIB to IV and an age of 18 yrs or older. The exclusion criteria included the absence of palpable tumor on clinical evaluation, disease of a histopathological type other than adenocarcinoma and early stage disease. This study was performed in accordance with the Declaration of Helsinki. All patients provided written informed consent and the study was approved by the institutional IRB (Comité de Investigación y Comité de Ética en Investigación - Instituto Nacional de Cancerología, 012/048/IMO/CB/806).

\section{Quantification of $5 \mathrm{hmC}$ in tumor DNA (initial biopsy)}

Fresh tissue samples were obtained from all patients at the time of the initial biopsy and were frozen at $-80^{\circ} \mathrm{C}$. For this analysis, the samples were thawed and homogenized for genomic DNA extraction, which was performed with the DNeasy Blood \& Tissue Kit (Qiagen, USA) using standard protocols. For $5 \mathrm{hmC}$ quantification, we used the Quest 5hmC DNA ELISA Kit (Zymo Research, USA). According to manufacturer, a very good correlation between ELISA and mass spectrometry results for $5 \mathrm{hmC}$ levels exists. The anti-5hmC antibody was diluted with the coating buffer, added to each well and incubated. After the wash steps were performed, the DNA was denatured at $98^{\circ} \mathrm{C}$ and was immediately placed on ice for $10 \mathrm{~min}$ to prevent the formation of double strands. The positive and negative control samples (provided by the kit manufacturer) were diluted to a final concentration of $1 \mathrm{ng} / \mu \mathrm{l}$ in the $1 \mathrm{X}$ ELISA buffer. One hundred microliters of each sample was added to each well in duplicate, and the plates were incubated for $1 \mathrm{hr}$. After the detection step was performed, the absorbance was read at $405-450 \mathrm{~nm}$. The $5 \mathrm{hmC}$ levels were determined from positive samples by linear regression models and were analyzed as continuous variables [see Supplementary Figure 1; after log-transformation Supplementary Figure 2].

\section{Histopathological assessment}

The histopathological assessment of the initial biopsy samples included an assessment of histological type, histological grade (according to the Nottingham classification), presence of inflammatory cells, presence or absence of an in situ component, lymphovascular invasion, perineural invasion, and other parameters. In addition, for the patients with locally advanced disease who received neoadjuvant treatment prior to surgery, the residual tumor burden was evaluated using the Miller-Payne grading system [38]. We used standard protocols to analyze the 
cell proliferation markers Ki67 (anti-Ki67, RTU, clone MIB-1; Dako North America, CA, USA) and MCM2 (anti-MCM2, 1: 200; clone MS-1726-PO/ US; Lab Vision Corporation NeoMarkers, Fremont, CA, USA). The immunostaining was evaluated visually, and the proportion of positive cells was scored by three independent experts and recorded. The intensity was recorded based on the recommendations of Detre et al. [38]. The presence of Ki67 was evaluated, and the index of cellular proliferation was expressed as the ratio of positive-stained nuclei to total nuclei in malignant cells.

\section{Statistical analysis}

A left-skewed, non-normal distribution was demonstrated ( $p$-value $<0.05$, Shapiro-Wilk test $[39,40]$ ) for the raw $5 \mathrm{hmC}$ levels; therefore, the data were log-transformed [see Supplementary Figure 1]. We explored the potential association between the variables using the $X^{2}$ test for the categorical variables and nonparametric tests for the continuous variables. After determining the variables potentially associated with $5 \mathrm{hmC}$ level, we ran mixed models including random intercepts for the replicates, using the following formula:

$$
\mathrm{Y}_{\mathrm{ji}}=b_{0}+b_{0 \mathrm{j}}+b_{1} \mathrm{X}_{1 \mathrm{ji}}+\varepsilon_{\mathrm{ji}}
$$

where, $b_{0 j}$ random intercept for individual, $\mathrm{j}=1, \ldots, \mathrm{N}, \mathrm{i}=1$, $\ldots, \mathrm{t}, Y=$ histological grade (G3 vs. G1-G2); $j$ (IDs) $=1, \ldots, \mathrm{N}$; $b_{0}=$ intercept; $b_{1}=$ estimate; $X_{1}=5 \mathrm{hmC}$ level (continuous, log-transformed variable); $b_{0 \mathrm{i}}=$ random intercept for the sample, measured in duplicate; and i (time) $=1, \ldots, \mathrm{t}$. We determined the association of $5 \mathrm{hmC}$ with high histological grade (low/intermediatevs. high); age (continuous variable), Ki67 proportion (continuous variable), and histological type (ductal vs. non-ductal adenocarcinoma) were included as covariates. For the survival analysis, the $5 \mathrm{hmC}$ levels were dichotomized from the log-transformed values according to the median distribution (low vs. high levels of $5 \mathrm{hmC}$ ). A two-sided alpha value of 0.05 was considered the level of significance.

\section{Results}

\section{Patients}

Table 1 summarizes the demographic, histopathological, and clinical characteristics of the patients included in the final analysis. The mean age of the cohort population was 50.12 yrs. (standard deviation [SD]: $9.54 \mathrm{yr}$ ) and the mean tumor size was $6.53 \mathrm{~cm}$ (SD: $3.06 \mathrm{~cm})$. The incidence of diabetes mellitus type 2 was $10.94 \%$, and the incidence of arterial hypertension was 16.75\%. Postmenopausal status was observed in $52.4 \%$ of the patients, and we found a high incidence of overweight (35.46\%) and obesity $(41.85 \%)$ in our population; the mean body mass index was $29.26 \mathrm{~kg} / \mathrm{m}^{2}$. The most frequently observed clinical stage was IIIA (40.42\%), followed by stage IIIB (19.85\%) and stage IIB (14.18\%). The most common histological type was infiltrating ductal carcinoma (85.1\%). A high tumor grade was observed in $53.90 \%$ of the patients, followed by an intermediate grade in $33.33 \%$, and a low grade in $12.8 \%$. According to the immunohistochemical analysis, $80.85 \%$ of the patients were found to be estrogen receptor and progesterone receptor (ER/PR)-positive; 5.67\%, HER2- positive; and 19\%, triple negative. We observed a median $5 \mathrm{hmC}$ level of $0.23 \%$ (SD: 0.59) (Table 1).

Table 1 Demographic, clinical and histopathologic characteristics of breast cancer patients* $(\mathrm{N}=141)$.

\begin{tabular}{lcc}
\hline Continuous variables & Mean & SD \\
\hline Age, yr & 50.12 & 9.54 \\
Tumor size, cm & 6.53 & 3.06 \\
Total 5hmC level, \% & 0.23 & 0.59 \\
Ki67, \% & 13.09 & 7.06 \\
MCM2, \% & 75.9 & 12.73 \\
Categorical variables & $\mathrm{n}$ & $\%$
\end{tabular}

Comorbidities

$\begin{array}{lcc}\text { Diabetes mellitus } & 15 & 10.94 \% \\ \text { Arterial hypertension } & 23 & 16.75 \%\end{array}$

Menopausal status

Postmenopausal

$B M I\left(\mathrm{~kg} / \mathrm{m}^{2}\right)$

$$
\begin{aligned}
& \text { Normal (19-24.9) } \\
& \text { Overweight (25-29) } \\
& \text { Obesity I (30-34) } \\
& \text { Obesity II (35-39.9) } \\
& \text { Obesity III (>40) }
\end{aligned}
$$

Histological type

Infiltrating ductal carcinoma
Infiltrating lobular carcinoma
Mixed
Other

Histological grade**

$\begin{array}{lll}1 & 18 & 12.80 \% \\ 2 & 47 & 33.33 \% \\ 3 & 76 & 53.90 \%\end{array}$

Phenotype

$\begin{array}{lcc}\text { ER/PR }(+) & 114 & 80.85 \% \\ \text { HER2 }(+)^{\star \star *} & 8 & 5.67 \% \\ \text { Triple negative*** } & 19 & 13.47 \%\end{array}$

ER: estrogen receptor; PR: progesterone receptor; SD: standard deviation. *Treated at the National Cancer institute - Mexico, 2013-2015. **Using the Nottingham scoring system. ***Percentage from all the population.

\section{$5 \mathrm{hmC}$ levels correlated negatively with age}

We observed a negative correlation between $5 \mathrm{hmC}$ levels and age, and this correlation was statistically significant in ER/PR-negative tumors $(r=-0.38, p$-value $<0.01)$ (Figure 1) and triple negative tumors $(r=-0.32, p$-value $=0.046)$. By bivariable analyses using a mixed effects linear model, we 
confirmed this association between age and $5 \mathrm{hmc}$ levels in ER/PR-negative tumors $(\beta=-0.028$, confidence interval 95\% [Cl 95\%]: $-0.045,-0.010, p$-value $=0.005)$ and in triple negative tumors ( $\beta=-0.023, \mathrm{Cl} 95 \%$ : $-0.044,-0.001, p$-value $=0.046$ ) in the overall cohort [see Supplementary Table].

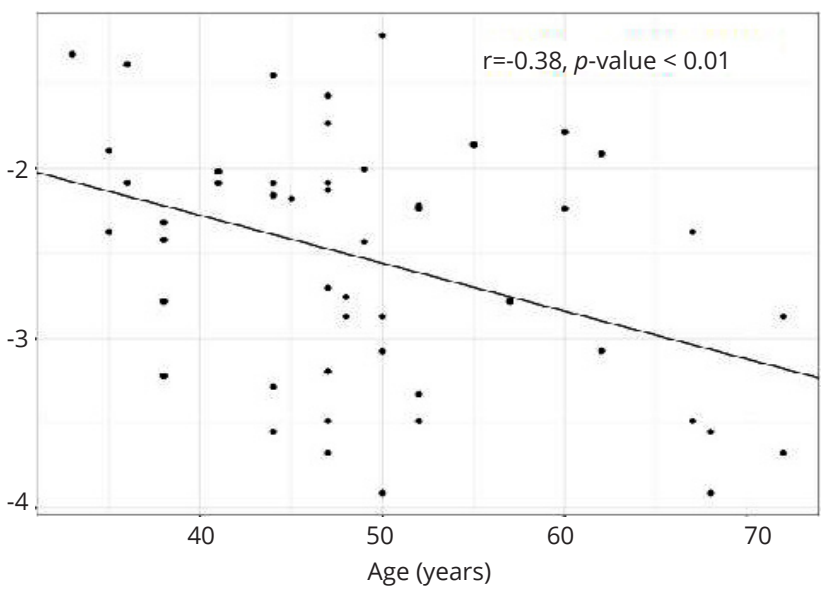

Figure 1 Correlation between age and $5 \mathrm{hmC}$ level in initial biopsy samples from estrogen and progesterone receptors (ER/PR)-negative tumors.

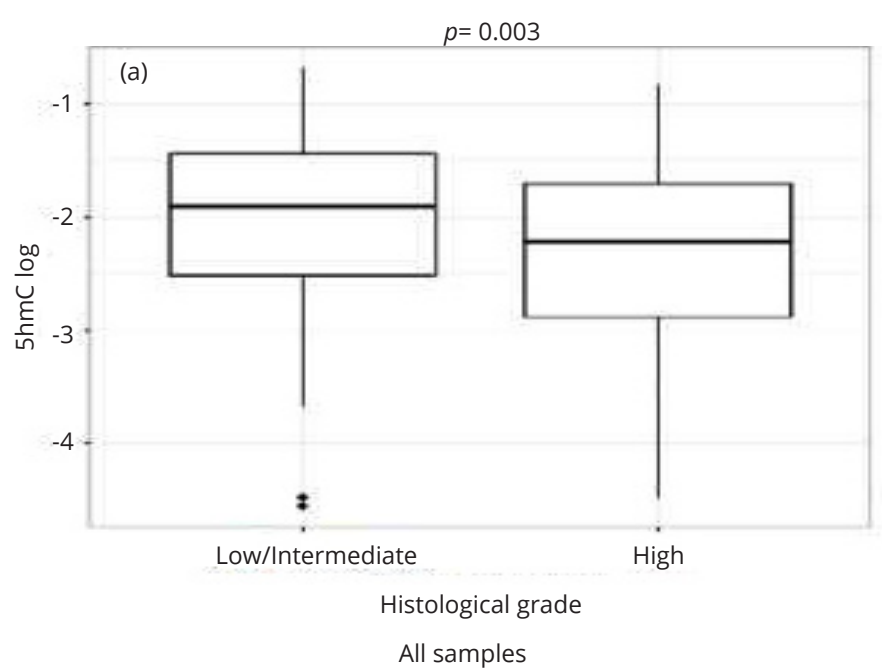

$5 \mathrm{hmC}$ levels were lower in tumors with a high histological grade

We observed lower $5 \mathrm{hmC}$ levels in tumors with a high histological grade than in tumors with a low/intermediate grade in all samples (Figure 2, Panel A, $p$-value $=0.003$ ) and in samples from only LABC patients (Figure 2, Panel B, $p$-value $=0.008$ ). Furthermore, by evaluating the association between histological grade and $5 \mathrm{hmC}$ levels with mixed effects logistic regression models, we observed that this association extended to ER/PR-positive tumors both in all samples ( $\beta=-0.243, \mathrm{Cl} 95 \%$ : $-0.470,-0.015, p$-value $=0.037$ ) and in the subset of LABC samples $(\beta=-0.36, \mathrm{Cl} 95 \%$ : $-0.608,-0.111, p$-value $=0.005)($ Table 2$)$.

5hmc levels were negatively associated with the cell proliferation markers Ki67 and minichromosome maintenance compex component 2 (MCM2) but not with tumor size, nodal status or clinical stage

We also found a negative correlation between $5 \mathrm{hmC}$ levels and the proliferation markers Ki67 $(r=-0.16, p$-value $=$ $0.005)$ and MCM2 ( $r=-0.21, p$-value $=0.030)$ (Figure 3). The correlation between $5 \mathrm{hmC}$ levels and MCM2 was evaluated only in a subset of samples ( $N=50$, random samples) with

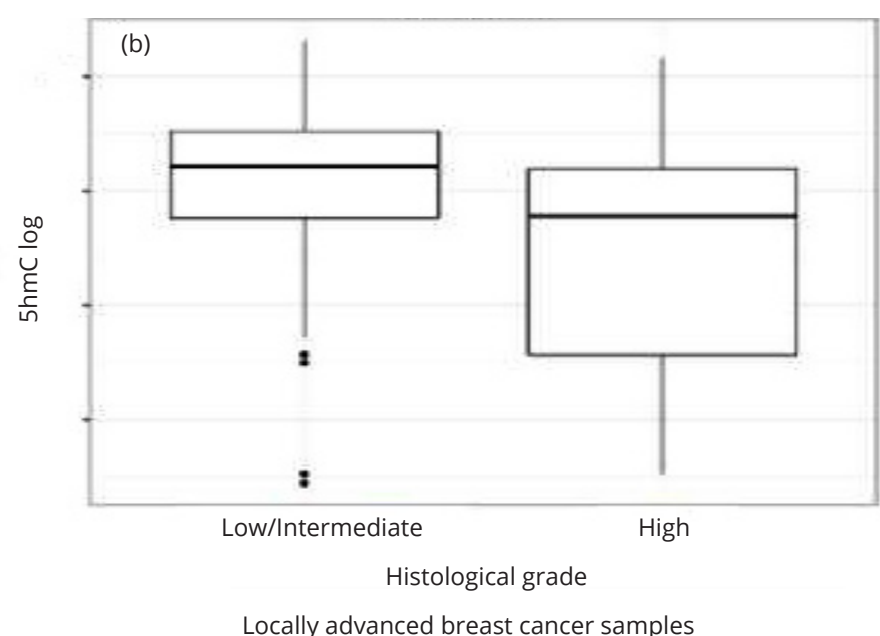

Figure $25 \mathrm{hmC}$ level by histological grade, assessed according to the Nottingham classification and dichotomized as high vs. low/intermediate grade. (a) shows the results from all the samples. (b) shows the results from the locally advanced breast cancer (LABC) samples only. Right panel shows the mixed effects logistic regression model showing the association between $5 \mathrm{hmC}$ levels and histologic grade in patients from the full cohort and LABC subset.

Table 2 The table shows the *Estimate for the association using mixed effects logistic regression model including random intercept for repetition (Association between $5 \mathrm{hmC}$ levels and histological grade).

\begin{tabular}{|c|c|c|c|c|c|}
\hline & & $N$ & $\beta^{*}$ & CL 95\% & $p$ value \\
\hline \multirow[t]{5}{*}{ Full cohort } & & 141 & -0.287 & $(-0.486,-0.087)$ & 0.005 \\
\hline & ER/PR (+) & 114 & -0.243 & $(-0.470,-0.015)$ & 0.037 \\
\hline & ER/PR (-) & 27 & 0.16 & $(-0.394,0.714)$ & 0.573 \\
\hline & HER2 (+) & 8 & 0.005 & $(-0.882,0.892)$ & 0.991 \\
\hline & Triple negative & 19 & 0.696 & $(-0.715,2.107)$ & 1.341 \\
\hline \multirow[t]{5}{*}{ LABC subset } & & 111 & -0.41 & $(-0.631,-0.188)$ & $<0.001$ \\
\hline & ER/PR (+) & 92 & -0.36 & $(-0.608,-0.111)$ & 0.005 \\
\hline & ER/PR (-) & 19 & 0.136 & $(-0.493,0.765)$ & 0.675 \\
\hline & HER2 (+) & 6 & 0.158 & $(-0.874,1.190)$ & 0.77 \\
\hline & Triple negative & 13 & 0.475 & $(-0.834,1.784)$ & 0.484 \\
\hline
\end{tabular}

ER: estrogen receptor; PR: progesterone receptor; HER2: human epidermal receptor 2; LABC: locally-advanced breast cancer; CI 95\%: confidence interval $95 \%$. Bold: Statistically significant variables associated with the dependent variable. 
available MCM2 levels. We did not observe any association between $5 \mathrm{hmC}$ levels and tumor size ( $p$-value $=0.881)$, nodal status ( $p$-value $=0.224)$, or clinical stage $(p$-value $=$ 0.441).

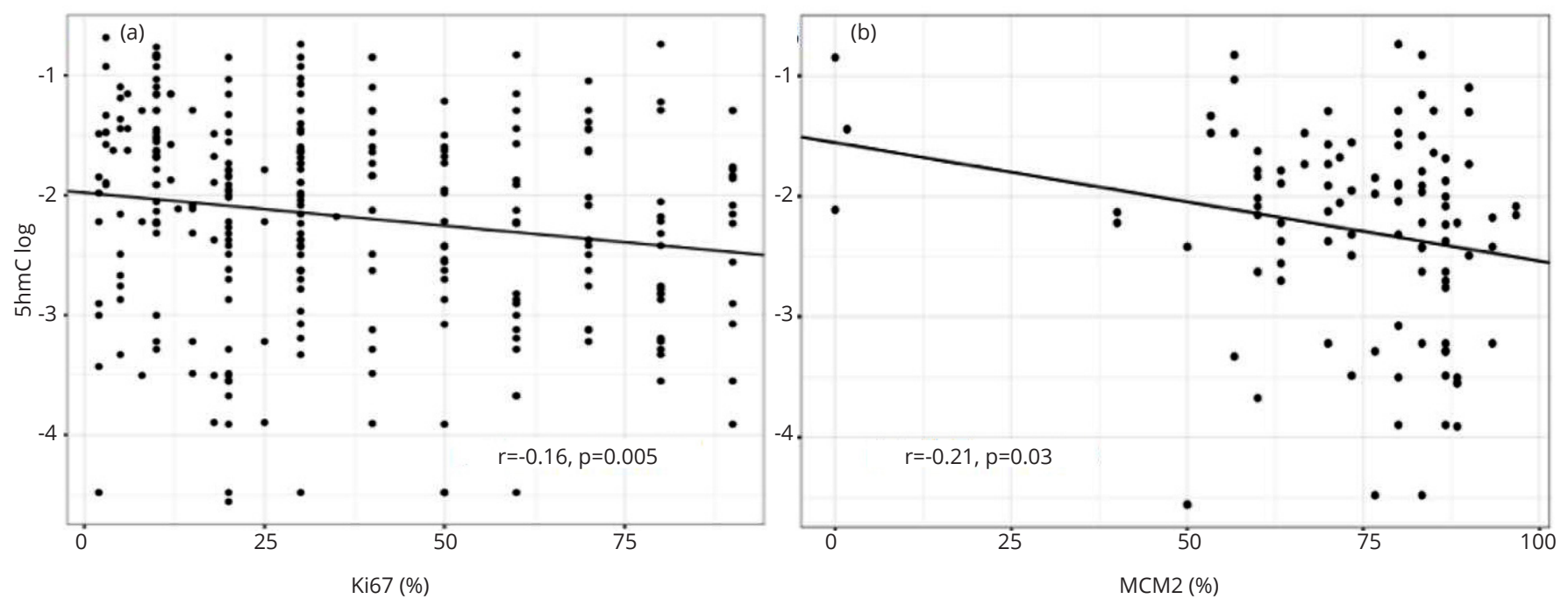

Figure 3 Correlation between $5 \mathrm{hmC}$ levels and the level of the cell proliferation markers Ki67 and MCM2, at baseline (diagnosis) in all samples. (a) $5 \mathrm{hmC}$ vs. Ki67; (b) 5hmC vs. MCM2.

Low 5hmC levels were independently associated with histopathological grade in $\angle A B C$

Based on our exploratory findings, we ran a multivariable analysis (adjusted for age, Ki67 level, and histological type) to determine whether $5 \mathrm{hmC}$ levels independently predict advanced histological grade. The following formula was used: $Y_{\mathrm{ji}}=b_{0}+b_{0 j}+b_{1} X_{1 \mathrm{ji}}+\ldots+b_{4} X_{4 \mathrm{ji}}+\varepsilon_{\mathrm{ji}}$, where, $b_{0 \mathrm{j}}$ random intercept for individual, $Y=$ histological grade, $b_{1-3}=$ estimate, $X_{1}=5 \mathrm{hmC}$ level (continuous, log-transformed variable), $X_{2}$ $=\mathrm{Ki} 67$ level (continuous variable), $X_{3}=$ age (continuous variable), $X_{4}=$ histological type (ductal vs. non-ductal), and $b_{0 \mathrm{i}}=$ random intercept for the sample, measured in duplicate. We did not find any significant association in the evaluation of all samples. However, in the evaluation of the subset of LABC samples, we found that histological grade $(\beta=0.156, C I 95 \%$ : 0.018, 0.294; $p$-value $=0.028)$, and age $(\beta=-0.006, \mathrm{Cl} 95 \%$ : $-0.001,-0.013 ; p$-value $=0.095)$ were independently associated with the presence of low levels of $5 \mathrm{hmC}$ (Table 3). Furthermore, we decided to determine whether $5 \mathrm{hmC}$ level was an independent predictor of histological grade. By running the model in reverse to determine whether $5 \mathrm{hmC}$ level can independently predict histological grade, we also found that low $5 \mathrm{hmc}$ levels were independently associated with advanced histological grade $(\beta=-0.077, \mathrm{Cl} 95 \%$ : $-0.142,-0.011 ; p$-value $=0.022)$ (Table 4).

Table 3 Association between characteristics of tumor and low level of $5 \mathrm{hmC}$ in the LABC patient subset*.

\begin{tabular}{lccc}
\hline & $\beta$ & $C l 95 \%$ & $p$-value \\
\hline Histological grade $^{\mathrm{a}}$ & 0.156 & $(0.018,0.294)$ & 0.028 \\
Ki67 $^{\mathrm{b}}$ & 0.010 & $(-0.001,0.021)$ & 0.054 \\
Age $^{\mathrm{b}}$ & 0.006 & $(-0.001,0.013)$ & 0.095 \\
Histological type $^{\mathrm{c}}$ & -0.050 & $(-0.259,0.160)$ & 0.643
\end{tabular}

Multivariable regression model for the association between clinical (age) and histopathological characteristics of tumor aggressiveness (histological grade and Ki67 level) and low levels of $5 \mathrm{hmC}$ in the LABC patient subset.

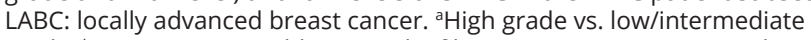
grade. ${ }^{b}$ Continuous variable. c Ductal infiltrating carcinoma vs. non-ductal carcinoma. ${ }^{*} \mathrm{n}=111$. Bold: Statistically significant variables associated with the dependent variable.

Table 4 Multivariable regression model for the association between $5 \mathrm{hmC}$ level and high histological grade* in LABC patients** $(n=111)$.

\begin{tabular}{lccc}
\hline & $\beta$ & Cl 95\% & p-value \\
\hline Histological grade & -0.077 & $(-0.142,-0.011)$ & 0.022 \\
Ki67 & 0.022 & $(0.014,0.030)$ & $<0.001$ \\
Age $^{\text {a }}$ & -0.001 & $(-0.007,0.004)$ & 0.637 \\
Histological type $^{\text {b }}$ & -0.013 & $(-0.176,0.150)$ & 0.875 \\
\hline
\end{tabular}

LABC: locally advanced breast cancer. 5hmC: 5-hydroxymethylcytosine. ${ }^{a}$ Continuous variables (log-transformed for $5 \mathrm{hmC}$ ). ${ }^{\mathrm{b}}$ Ductal infiltrating carcinoma vs. non-ductal carcinoma. *Dependent variable (histological grade) was dichotomized (grade 3 vs. grades 1 and 2 ). **Treated at the National Cancer institute - Mexico, 2013-2015. Bold: Statistically significant variables associated with the dependent variable.

\section{5 hm C level and prognosis}

The median follow-up time of the patients in the cohort was 43 mons. During the follow-up period, we observed disease relapse in $16.3 \%$ and death in $9.9 \%$ of the total cohort population. We found a pathologic complete response (PCR) in $19.9 \%$ of the LABC patients, and we did not observe a difference in $5 \mathrm{hmC}$ level among the patients who experienced PCR. We did not find any differences in survival prognosis according to $5 \mathrm{hmC}$ level [see Supplementary Figures 3 and 4].

\section{Discussion}

In the past decade, increasing evidence has suggested that epigenetic regulation plays a vital role in the initiation and progression of human cancer. Not merely a transient intermediate in the DNA active demethylation process, $5 \mathrm{hmC}$ is reported to be enriched and stable in mammalian tissues and recognized by specific $5 \mathrm{hmC}$-binding proteins 
[37]. In the present study, we found a statistically significant association between lower level of $5 \mathrm{hmC}$ and important histopathological characteristics of breast cancer tumors that define prognosis. These characteristics include parameters such as high tumor grade, invasive ductal carcinoma subtype, and expression of the wellknown marker of cell proliferation, Ki67, and also, MCM2. Furthermore, these findings were determined by using a reliable quantitative technique not susceptible to subjective interpretation to analyze a set of fresh frozen tissue samples from a prospective cohort of locally advanced and advanced breast cancer patients at a large cancer-devoted institute. Thus, the bias in data acquisition was reduced due to the homogeneity in patient recruitment and the high standards followed during sample processing.

These results support the current identity of low $5 \mathrm{hmC}$ level as an important factor present in different highly aggressive cancers, such as melanoma, gastric cancer, and, as shown in our study, breast cancer. Furthermore, our results expound on the role of $5 \mathrm{hmC}$ as an important prognostic factor by showing that a low $5 \mathrm{hmC}$ level is associated with higher histological grade and higher levels of the cellular proliferation markers Ki67 and MCM2. To our knowledge, this is the first report of an association between this recently identified epigenetic mark and histopathological characteristics of locally advanced and advanced breast cancer patients at the time of diagnosis. This association suggests that the loss of $5 \mathrm{hmC}$ is linked to a more aggressive phenotype and is associated with worse outcomes.

Epigenetic changes in somatic cells have frequently been associated with the carcinogenic process and tumor progression in an array of different neoplasms. In this regard, cytosine methylation at the carbon 5 position, which results in the formation of 5-methylcytosine $(5 \mathrm{mC})$, has been a relevant epigenetic change to date $[39,41,42]$.

Cytosine methylation is a key process in gene transcription. In human cancer, global hypomethylation is a hallmark of disease, along with hypermethylation in specific areas in the promoter regions of tumor suppressor genes that render these genes silenced. In addition, 5-hydroxymethylation has been shown to be not only an intermediate step in the process of $5 \mathrm{mC}$ demethylation but also an actual epigenetic phenomenon in its own right $[25,43,44]$.

The role of $5 \mathrm{hmC}$ in normal cellular processes is beginning to be elucidated. Research has suggested that $5 \mathrm{hmC}$ plays a significant role in the transcriptional regulation of genes related to the differentiation process [27]. Furthermore, $5 \mathrm{hmC}$ level in cancer cells have been shown to be altered in hematological malignancies [28, 29] and in different solid tumors [30-33]. Similarly, Chen and colleagues reported significantly lower levels of $5 \mathrm{hmC}$ in renal cell carcinoma tissue than in normal kidney tissue samples. Interestingly, low levels of $5 \mathrm{hmC}$ were also associated with shorter overall survival. Moreover, Tsai and colleagues found that low levels of $5 \mathrm{hmC}$ was associated with poor diseasespecific survival and disease-free survival in breast cancer patients, particularly in those with ER/PR-negative tumors [35]. Additionally, Larson and colleagues suggested that, in melanoma, a decrease in $5 \mathrm{hmC}$ is associated with an increasing dysplasia grade and higher histological grade $[31,45]$. Ultimately, these data are consistent with our finding that a decrease in $5 \mathrm{hmC}$ level is correlated with a higher histological grade, as reported by Larson et al. for melanoma, and with a worse clinical outcome, as reported by Tsai et al. [35] for breast cancer.

Most studies evaluating $5 \mathrm{hmC}$ levels in cancer tissue samples have been performed using non-standardized immunohistochemical staining [30-35]. Mastery of the standardization and interpretation of the staining patterns generated by this method requires a considerable learning curve, and reports have shown frequent inter- and intraobserver variability regarding positive and negative staining patterns [46]. Incontrast, ourimmunohistochemical analysis was performed on fresh frozen tissue samples using a highly specific quantitative technique, that has been shown to be equivalent to quantification of $5 \mathrm{hmC}$ by mass spectrophotometry (the current gold standard). This technique, besides being accurate and sensitive to very low amounts of $5 \mathrm{hmC}$, requires small quantities of free DNA, as advised by the manufacturer. Additionally, the ELISA method used is very simple and straightforward; therefore, it can be applied in the laboratory setting without the need for high-end technology. Moreover, our analysis was performed using strict technical controls to ensure the validity and accuracy of the $5 \mathrm{hmC}$ measurements. In addition, the clinical data were retrieved from a prospective cohort of locally advanced and advanced breast cancer patients, thus reducing recall bias, recollection bias, and recruited patient heterogeneity. To our knowledge, this is the first report of the use of a quantitative technique to determine $5 \mathrm{hmC}$ levels in fresh frozen tissue from initial biopsies in a prospective cohort of breast cancer patients.

The main limitation in our current study is the follow-up time of only 3 yrs., which made the analysis of results regarding relevant clinical endpoints such as diseasespecific survival, relapse-free survival, and overall survival difficult. Another limitation of the current study is the small number of cases of specific tumor subtypes; our cohort of patients mainly comprised ER/PR-positive and ER/PRnegative patients in locally advanced and advanced clinical stages, and the generalizability of the results is thus limited. However, despite this limitation, we were able to observe associations that correlate biologically (namely, higher tumor grade and increased levels of proliferation markers). On the other hand, ELISA measurements may show technical concerns regarding to the poor reproducibility of the results; however, manufacturer guarantees similar and reproducible results obtained with this kit and mass spectrometry, which give us a level of confidence in our measurements.

\section{Conclusions}

Overall, this study supports the hypothesis that the loss of $5 \mathrm{hmC}$ has prognostic value as a marker of adverse prognosis in locally advanced and advanced breast cancer patients and that low $5 \mathrm{hmc}$ level correlate well with a more aggressive phenotype, as determined by a higher histological grade and higher levels of the proliferation markers Ki67 and MCM2. Further studies involving the 
specific genes affected by the loss of $5 \mathrm{hmC}$ and the pathways involved are currently underway, and these studies should help elucidate the role of this novel epigenetic biomarker.

\section{Ethics approval and consent to participate}

This study was performed in accordance with the Declaration of Helsinki. All patients provided written informed consent and the study was approved by the institutional IRB.

\section{Acknowledgements}

We thank Clementina Castro-Hernández for the critical review of this manuscript.

\section{Funding}

This work was supported by the National Institutes of Health [grant R21ES027087] and by Consejo Nacional de Ciencia y Tecnología - Mexico (CONACYT, grant 289503).

\section{Competing interests}

The authors declare that they have no competing interests.

\section{List of abbreviations}

5hmc:5-hydroxymethylcytosine;5mC:5-methylcytosine;Cl: Confidence interval; ELISA: Enzyme-linked immunosorbent assay; ER: Estrogen receptor; HER2: Human epidermal growth factor receptor-type2; LABC: Locally advanced breast cancer; MCM2: Minichromosome maintenance complex component 2; PCR: Pathologic complete response; PR: Progesterone receptor; SD: Standard deviation; TET1-3: Ten-eleven translocation methylcytosine dioxygenase 1-3.

\section{Authors' contributions}

OPC, MR and DP carried out DNA extraction and quantification of 5-hydroxymethylcytosine. OPC, DM, $\mathrm{GL}, \mathrm{ALP}, \mathrm{CC}$ collected clinical and histopathological data. CVG, PCG, EB, JDC, YV and CC obtained tumor samples and achieved patient selection. LS carried out MCM2 determination. EC, NR and DP design and run statistical analyses. OPC, MA, DC, LAH and DP contributed with manuscript writing and in the results discussion.

\section{Availability of data and material}

The data that support the findings of this study are available from the National Cancer institute - Mexico (Dr. Diddier Prada) but restrictions apply to the availability of these data, which were used under license for the current study, and so are not publicly available. Data are however available from the authors upon reasonable request and with permission of the National Cancer Institute - Mexico.

\section{Supplementary data}

Supplementary data associated with this article can be found, at http://nobleresearch.org/Doi/10.14312/20524994.2020-1. These data include Supplementary Table and Figures.

\section{References}

[1] Bray F, Ferlay J, Soerjomataram I, Siegel RL, Torre LA, et al. Global cancer statistics 2018: GLOBOCAN estimates of incidence and mortality worldwide for 36 cancers in 185 countries. CA Cancer J Clin. 2018; 68(6):394-424.

[2] Smart CR, Byrne C, Smith RA, Garfinkel L, Letton AH, et al. Twenty-year follow-up of the breast cancers diagnosed during the Breast Cancer Detection Demonstration Project. CA Cancer J Clin. 1997; 47(3):134149.

[3] Bland KI, Menck HR, Scott-Conner CE, Morrow M, Winchester DJ, et al. The National Cancer Data Base 10-year survey of breast carcinoma treatment at hospitals in the United States. Cancer 1998; 83(6):12621273.

[4] Arce-Salinas C, Lara-Medina FU, Alvarado-Miranda A, Castañeda-Soto N, Bargalló-Rocha E, et al. Evaluation of breast cancer treatment at a tertiary-level institution with Popular Health Insurance in Mexico. Rev. Investig Clin. 2012; 64(4):9-16.

[5] López-Carrillo L, Torres-Sánchez L, López-Cervantes M, Rueda-Neria C. Identification of malignant breast lesions in Mexico. Salud Publica Mex. 2001; 43(3):199-202.

[6] Villarreal-Garza C, Aguila C, Magallanes-Hoyos MC, Mohar A, Bargalló $\mathrm{E}$, et al. Breast cancer in young women in Latin America: an unmet, growing burden. The Oncologist. 2013; 18(12):1298-1306.

[7] Flores-Luna L, Salazar-Martínez E, Duarte-Torres RM, Torres-Mejía $G$, Alonso-Ruiz $P$, et al. Prognostic factors related to breast cancer survival. Salud Publica Mex. 2008; 50(2):119-125.

[8] Singletary SE, Allred C, Ashley P, Bassett LW, Berry D, et al. Revision of the American Joint Committee on Cancer staging system for breast cancer. J Clin Oncol. 2002; 20(17):3628-3636.

[9] National Cancer Institute: Surveillance, epidemiology, and end results program. SEER. 2019. Accessed on 20 February 2019 from: https:// seer.cancer.gov/index/statfacts/html/breast.html

[10] Cimino-Mathews A, Verma S, Figueroa-Magalhaes MC, Jeter SC, Zhang Z, et al. A Clinicopathologic analysis of 45 patients with metaplastic breast carcinoma. Am J Clin Pathol. 2016; 145(3):365-372.

[11] Ezeani MC, Onyenekwe CC, Meludu SC, Ezeani UU, Chianakwana G, et al. Regulation of DNA methylation in female subjects with increased (Pathological) level of circulating immune complexes and breast tumours. Jpn J Cancer Oncol. Res. 2018; 2(1):1006.

[12] Feinberg AP. The key role of epigenetics in human disease prevention and mitigation. N Engl J Med. 2018; 378(14)1323-1334.

[13] Esteller M. Epigenetics in cancer. N Engl J Med. 2008; 358(11):11481159.

[14] Esteller M. Cancer epigenomics: DNA methylomes and histonemodification maps. Nat Rev Genet. 2007; 8(4):286-298.

[15] Ballestar E, Paz MF, Valle L, Wei S, Fraga MF, et al. Methyl-CpG binding proteins identify novel sites of epigenetic inactivation in human cancer. EMBO J. 2003; 22(23):6335-6345.

[16] Mariani CJ, Madzo J, Moen EL, Yesilkanal A, Godley LA. Alterations of 5-hydroxymethylcytosine in human cancers. Cancers 2013; 5(3):786814.

[17] Tahiliani M, Koh KP, Shen Y, Pastor WA, Bandukwala H, et al. Conversion of 5-methylcytosine to 5-hydroxymethylcytosine in mammalian DNA by MLL partner TET1. Science. 2009; 324(5929):930-935.

[18] Kriukienè E, Liutkevičiūtè Z, Klimašauskas S. 5-Hydroxymethylcytosine-the elusive epigenetic mark in mammalian DNA. Chem Soc Rev. 2012; 41(21):6916-6930.

[19] Cimmino L, Abdel-Wahab O, Levine RL, Aifantis I. TET family proteins and their role in stem cell differentiation and transformation. Cell Stem Cell. 2011; 9(3):193-204.

[20] Dahl C, Grønbæk K, Guldberg P. Advances in DNA methylation: 5-hydroxymethylcytosine revisited. Clin Chim Acta 2011; 412(1112):831-836.

[21] Ficz G, Branco MR, Seisenberger S, Santos F, Krueger F, et al. Dynamic regulation of 5-hydroxymethylcytosine in mouse ES cells and during differentiation. Nature. 2011; 473(7347):398-402.

[22] Gu TP, Guo F, Yang H, Wu HP, Xu GF, et al. The role of Tet3 DNA dioxygenase in epigenetic reprogramming by oocytes. Nature 2011; 477(7366):606-610.

[23] Guo JU, Su Y, Zhong C, Ming GL, Song H. Emerging roles of TET proteins and 5-hydroxymethylcytosines in active DNA demethylation and beyond. Cell Cycle. 2011; 10(16):2662-2668.

[24] He YF, Li BZ, Li Z, Liu P, Wang Y, et al. Tet-mediated formation of 5-carboxylcytosine and its excision by TDG in mammalian DNA. Science. 333(6047):1303-1307. 
[25] Ito S, Shen L, Dai Q, Wu SC, Collins LB, et al. Tet proteins can convert 5-methylcytosine to 5-formylcytosine and 5-carboxylcytosine. Science. 2011; 333(6047):1300-1303.

[26] Jin SG, Wu X, Li AX, Pfeifer GP. Genomic mapping of 5-hydroxymethylcytosine in the human brain. Nucleic Acids Res. 2011; 39(12):5015-5024.

[27] Pastor WA, Pape UJ, Huang Y, Henderson HR, Lister R, et al. Genomewide mapping of 5-hydroxymethylcytosine in embryonic stem cells. Nature. 2011; 473(7347):394-397.

[28] Ko M, Huang Y, Jankowska AM, Pape UJ, Tahiliani M, et al. Impaired hydroxylation of 5-methylcytosine in myeloid cancers with mutant TET2. Nature. 2010; 468(7325):839-843.

[29] Konstandin N, Bultmann S, Szwagierczak A, Dufour A, Ksienzyk B, et al. Genomic 5-hydroxymethylcytosine levels correlate with TET2 mutations and a distinct global gene expression pattern in secondary acute myeloid leukemia. Leukemia. 2011; 25(10):1649-1652.

[30] Haffner MC, Chaux A, Meeker AK, Esopi DM, Gerber J, et al. Global 5-hydroxymethylcytosine content is significantly reduced in tissue stem/progenitor cell compartments and in human cancers. Oncotarget. 2011; 2(8):627-637.

[31] LianCG,XuY,CeolC,WuF, LarsonA, etal.Lossof5-hydroxymethylcytosine is an epigenetic hallmark of melanoma. Cell. 2012; 150(6):1135-1146.

[32] Xu Y, Wu F, Tan L, Kong L, Xiong L, et al. Genome-wide regulation of $5 \mathrm{hmC}, 5 \mathrm{mC}$, and gene expression by Tet 1 hydroxylase in mouse embryonic stem cells. Mol Cell. 2011; 42(4):451-464.

[33] Yang H, Liu Y, Bai F, Zhang JY, Ma SH, et al. Tumor development is associated with decrease of TET gene expression and 5-methylcytosine hydroxylation. Oncogene. 2013; 32(5):663-669.

[34] Shi X, Yu Y, Luo M, Zhang Z, Shi S, et al. Loss of 5-Hydroxymethylcytosine Is an Independent Unfavorable Prognostic Factor for Esophageal Squamous Cell Carcinoma. PloS One. 2016; 11(4):e0153100.

[35] Tsai KW, Li GC, Chen $\mathrm{CH}$, Yeh MH, Huang JS, et al. Reduction of global 5-hydroxymethylcytosine is a poor prognostic factor in breast cancer patients, especially for an ER/PR-negative subtype. Breast Cancer Res. Treat. 2015; 153(1):219-234.

[36] Strand SH, Hoyer S, Lynnerup AS, Haldrup C, Storebjerg TM, et al. High levels of 5-hydroxymethylcytosine $(5 \mathrm{hmC})$ is an adverse predictor of biochemical recurrence after prostatectomy in ERG-negative prostate cancer. Clin Epigenetics. 2015; 7:111.

[37] Tzanninis IG, Kotteas EA, Ntanasis-Stathopoulos I, Kontogianni P, Fotopoulos G. Management and Outcomes in Metaplastic Breast Cancer. Clin Breast Cancer. 2016; 16(6):437-443.

[38] Ogston KN, Miller ID, Payne S, Hutcheon AW, Sarkar TK, et al. A new histological grading system to assess response of breast cancers to primary chemotherapy: prognostic significance and survival. Breast. 2003; 12(5):320-327.

[39] Detre S, Saclani Jotti G, Dowsett M. A 'quickscore' method for immunohistochemical semiquantitation: validation for oestrogen receptor in breast carcinomas. J Clin Pathol. 1995; 48(9):876-878.

[40] Ghasemi A, ZahediasI S. Normality Tests for Statistical Analysis: a guide for non-statisticians. Int J Endocrinol Metab. 2012; 10(2):486-489.

[41] Feinberg AP, Ohlsson R, Henikoff S. The epigenetic progenitor origin of human cancer. Nat Rev Genet. 2006; 7(1):21-33.

[42] Herrera LA, Prada D, Andonegui MA, Dueñas-González A. The epigenetic origin of aneuploidy. Curr Genomics. 2008; 9(1):43-50.

[43] Chen K, ZhangJ, Guo Z, Ma Q, Xu Z, et al. Loss of 5-hydroxymethylcytosine is linked to gene body hypermethylation in kidney cancer. Cell Res. 2016; 26(1):103-118.

[44] Ehrlich, M. DNA hypomethylation in cancer cells. Epigenomics. 2009; 1(2):239-259.

[45] Larson AR, Dresser KA, Zhan Q, Lezcano C, Woda BA, et al. Loss of 5-hydroxymethylcytosine correlates with increasing morphologic dysplasia in melanocytic tumors. Mod Pathol. 2014; 27(7):936-944.

[46] Lawrie CH, Ballabio E, Soilleux E, Sington J, Hatton CS, et al. Inter- and intra-observational variability in immunohistochemistry: a multicentre analysis of diffuse large B-cell lymphoma staining. Histopathology. 2012; 61(1):18-25. 